\title{
Risk stratification by injury distribution in polytrauma patients - does the clavicular fracture play a role?
}

Klemens Horst, ${ }^{*}$ Thomas Dienstknecht, Roman Pfeifer, Miguel Pishnamaz, Frank Hildebrand and Hans-Christoph Pape

\begin{abstract}
Background: Thoracic and extremity injuries are common in polytraumatized patients. The clavicle limits the upper thoracic cage and connects the body and upper extremities. It is easy to examine and is visible on standard emergency room radiographs. We hypothesize that clavicular fracture in polytrauma patients indicates the presence of further injuries of the upper extremities, head, neck and thorax.

Material and methods: Retrospective study including patients admitted between 2008 and 2012 to a level-I trauma center. Inclusion criteria: ISS > 16, two or more injured body regions, clavicular fracture. Control group: patients admitted in 2011, ISS > 16, two or more injured body regions, no clavicular fracture. Patient information was obtained from the patients' charts; evaluation of radiographic findings was performed; scoring was based on the Abbreviated Injury Scale (AIS) and Injury Severity Score (ISS) AIS/ISS; data were analyzed using Pearson's correlation and the Mann-Whitney U-test in SPSS (version 11.5.1); graphs were drawn using EXCEL ${ }^{\oplus}$.

Results: Thirty-four patients with clavicular fracture $(C+)$ and 40 without (C-) were included; the mean ISS was 25 (range 16-57), $m=70 \%, f=30 \%$; age 43.3 years (range 9-88); clavicular fractures were positively correlated with severe thoracic ( $p=0.011$, OR 4.5: KI 1.3-15.3), external ( $p<0.001$, OR 9.2: KI 2.7-30.9) and upper extremity injuries $(p<0.001$, OR 33.2: KI 6.9-16.04 resp. $p=0.004$, OR 12.5: Kl 1.5-102.9). $C+$ showed a lower head/neck AIS ( $p=0.033)$, higher thorax AIS $(p=0.04)$, arm/shoulder AIS $(p=0.001)$ and external AIS $(0.003)$ than C-. Mean hospital stay and ICU treatment time were longer in the $C+$ group $(p=0.001$ and $p=0.025$ respectively).

Conclusion: A clavicular fracture can be diagnosed easily and may be used as a pointer for further thoracic and upper extremity injuries in polytrauma patients that might have been otherwise missed. Special attention should be paid on second and tertiary survey.
\end{abstract}

\section{Introduction}

Accidents are the leading cause of death in children and young adults. In 2010 20,242 people died in Germany following a severe accident [1]. Management of seriously injured patients is highly demanding and interdisciplinary cooperation is necessary. In 2010 the German Society for Traumatology (DGU) published the first S3-Guideline to optimize management in polytraumatized patients [2]. Typically, the most severe injuries are found in the thoracic and abdominal area and in the long bones. Once the

\footnotetext{
* Correspondence: khorst@ukaachen.de

Department of Trauma and Reconstructive Surgery, University Hospital RWTH Aachen, Pauwelsstreet 30, 52074 Aachen, Germany
}

patient is brought to a Trauma Center, standardized algorithms of diagnostic procedures and treatment are performed. Due to the nature of polytraumatized patients, life-threatening injuries are the first priority. Overlooked and delayed diagnoses are common problems in the treatment of polytraumatized patients [3]. Buduhan et al. reported that $33.3 \%$ of upper extremity injuries were overlooked [4], while Kalemoglu et al. reported a rate of $38.2 \%$ [5]. In terms of wrist, hand and arm injuries, Guly reported rates of $17.2 \%, 21.7 \%$ and $15.1 \%$ of missed injuries, respectively [6]. Other authors reported that 4-8\% (wrist/hand) and 11-12\% (arm) of injuries of the upper extremities were missed. As thoracic injuries are common in polytrauma, taking plain thoracic $\mathrm{x}$-rays during the 
emergency procedure is widely accepted. Beside typical thoracic injuries such as rip series fracture, hemopneumothorax or suspicious mediastinal signs, additional information such as the presence of clavicular fractures can be obtained from the $\mathrm{x}$-ray. We hypothesize that a clavicular fracture in polytraumatized patients is suggestive of additional upper extremity injuries. Additionally we evaluate the circumstances that are responsible for the diagnosis of missed injuries in the upper extremity area and describe strategies to limit these pitfalls.

\section{Material and methods}

This retrospective study included patients examined between 2008 and 2012. Inclusion criteria: clavicular fracture, ISS > 16 and injury to two or more physical regions or organ systems, where at least one injury was life threatening. This group was named $\mathrm{C}+$. Inclusion criteria for the control group were the same except that these patients had no clavicular fracture. Consecutive patients that were diagnosed and treated in 2011 were included in the control group, named C-. Patient information was obtained from the patients' charts and the hospital's electronic database. Plain radiographs (chest and pelvic radiographs from primary survey; plain radiographs and CT scans of each injured region that were taken on day of admission or later during hospital stay) were evaluated by independent investigators (radiologists and trauma surgeons) and trauma severity was scored using the Abbreviated Injury Scale (AIS-90) and the Injury Severity Score. Statistical analysis was carried out using SPSS (version 11.5.1). Pearson's correlation, the Mann-Whitney $U$-test and Chi-Square tests were used. A power analysis was performed using $G$ *Power (version 3.1.5) and $d=0.8$. Means and standard deviation are given. Statistical significance was defined as $\mathrm{p}=0.05$. Graphs were drawn using Microsoft EXCEL .

\section{Results}

In total 74 patients met the inclusion criteria. Thirtyfour patients had a clavicular fracture (age $46 \pm 20$ years, $\mathrm{m}=22, \mathrm{f}=12$ ) and 40 patients had no clavicular fracture (age $41 \pm 19$ years, $\mathrm{m}=30, \mathrm{f}=10$ ). Patients with a clavicular fracture were more frequently involved in road accidents (OR 3.97, KI 1.45-10.88, p = 0.006) than those without, and with the exception of falls from a height over two meters (OR 0.09, KI 0.01-0.75, p=0.007), no significant associations with other trauma mechanisms were observed (Figure 1).

The mean hospital stay was $23 \pm 15$ days in the $\mathrm{C}+$ group and $17 \pm 28(\mathrm{p}=0.001)$ in the $\mathrm{C}$ - group. Patients with a clavicular fracture remained in the intensive care unit for $5 \pm 3$ days, whereas patients without a fracture of the clavicle remained for $4 \pm 7$ days $(p=0.025)$ days. The AIS for thoracic injuries as well as injuries of the arm/shoulder region and external injuries was higher in patients with fracture of the clavicle. The AIS for head injuries was higher in polytrauma patients without a clavicular fracture (Table 1). Five patients in the $\mathrm{C}+$ group died, three of them during emergency room procedures. Seven patients in the C-group died during hospital stay.

The ISS was higher in patients with clavicular fracture $(25.79 \pm 7.03)$ than in patients without clavicular fracture $(24.63 \pm 10.39 ; \mathrm{p}=0.047)$.

Correlation analysis of the AIS and ISS score of different body regions showed that there was a positive correlation between clavicular fracture and injuries of the thorax, arm/shoulder (AIS), extremities (ISS) and external injuries (AIS/ISS). Death was not correlated with the concomitant presence or absence of clavicular fracture (Table 2).

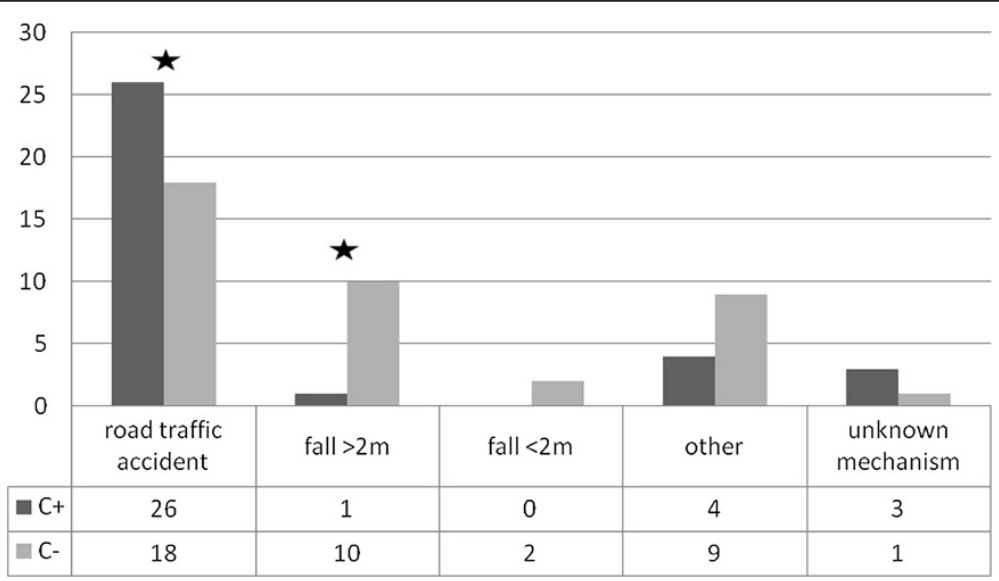

Figure 1 Trauma mechanisms, $\mathrm{p}<0.05$. 
Table 1 Mean AIS in polytrauma patients with and without clavicular fracture

\begin{tabular}{lllll}
\hline Location & Group & AIS & SD & $\boldsymbol{p}$ \\
\hline Head & C+ & 1.24 & 1.76 & 0.033 \\
\multirow{2}{*}{ Thorax } & C- & 2.20 & 2.00 & \\
& C+ & 2.71 & 1.29 & 0.040 \\
Arm/shoulder & C- & 1.93 & 1.61 & \\
& C+ & 1.94 & 0.55 & 0.001 \\
External & C- & 0.50 & 0.82 & \\
& C+ & 0.97 & 0.46 & 0.003 \\
& C- & 0.58 & 0.71 & \\
\hline
\end{tabular}

The odds ratios of clavicular fracture and associated injures in AIS/ISS body regions are shown in Table 3.

\section{Discussion}

The number of people dying due to an accident continues to rise. While 18,527 cases were reported in Germany in 2007, 20,242 people died in 2010 [1]. There have been many attempts to prevent accidents, and the management of seriously injured patients has improved. Life-threatening injuries are typically found in the thoracic and abdominal area and in the long bones [2]. For this reason, these areas are the focus of attention initially. Therefor plain $\mathrm{x}$-rays of the chest and pelvis as well as FAST (focus assessed sonography in trauma) is used in our institution. Nevertheless, overlooked and delayed diagnoses remain common problems in polytrauma patients. Pfeifer et al. reported that up to $22.3 \%$ of clinically significant injuries are missed in polytraumatized patients [3], although the reported rate of missed injuries varies widely (1.3-39\%).

Injuries in the upper extremity region may not be immediately life threatening but they have a massive impact on limb survival, patient convalescence and rehabilitation. In all cases early diagnosis and correct treatment is important [7-11]. When focusing on the upper extremities, $33.3 \%$ [4] to $38.2 \%$ [5] of injuries are reported to have been missed. Guly distinguished between injuries of the wrist,

Table 2 Pearson's correlation in polytrauma patients with and without clavicular fracture using AIS/ISS scoring regions

\begin{tabular}{llcccc}
\hline \multirow{2}{*}{ Location } & \multicolumn{2}{c}{$\begin{array}{c}\text { Clavicular } \\
\text { fracture n\% }\end{array}$} & $\begin{array}{c}\text { Pearson's } \\
\text { correlation coefficient }\end{array}$ & $\boldsymbol{p}$ \\
\hline AIS & Thorax & 32 & $40.5 \%$ & 0.294 & 0.011 \\
& Arm/shoulder & 30 & $43.2 \%$ & 0.629 & $>0.001$ \\
& External & 32 & $40.5 \%$ & 0.451 & $>0.001$ \\
\multirow{2}{*}{ ISS } & Chest & 32 & $40.5 \%$ & 0.294 & 0.011 \\
& Extremities & 33 & $44.6 \%$ & 0.332 & 0.004 \\
& External & 30 & $43.2 \%$ & 0.565 & $>0.001$ \\
\multirow{2}{*}{ Death } & 5 & $6.8 \%$ & -0.038 & 0.749 \\
\hline
\end{tabular}

Table 3 Odds ratios in polytrauma patients with clavicular fractures and associated injuries

\begin{tabular}{lllll}
\hline Location & $\boldsymbol{n}$ & Odds ratio & $\boldsymbol{K I}$ & $\boldsymbol{p}$ \\
\hline Thorax/chest & 74 & 4.5 & $1.32-15.30$ & 0.016 \\
Arm/shoulder & 74 & 33.23 & $6.88-16.42$ & 0.001 \\
Extremities & 74 & 12.52 & $1.5-102.94$ & 0.004 \\
External & 74 & 9.17 & $2.7-30.90$ & $>0.001$ \\
\hline
\end{tabular}

hand and arm and reported rates of 17.2\% (wrist), 21.7\% (hand) and 15.1\% (arm) of undetected injuries [6]. Others reported $4-8 \%$ (wrist/hand) and 11-12\% (arm) [12,13] of missed injuries of the upper extremities. Aim of the present study was to find a co-incidence of easily diagnosed injuries that may help to identify concomitant trauma of the upper limbs. Although the emphasis is not specifically on missed injuries in this study, the found correlations help to focalize on additional injuries of the upper extremity region. The importance of treatment of upper limb injuries is obvious when the long-term results are considered. Stalp et al. reported that $16 \%$ of patients had moderate or severe restrictions after injuries of the upper extremities according to the Musculoskeletal Function Assessment [14]. Mkandawire et al. found that after 5 years patients with severe trauma (ISS $>15$ ) and shoulder girdle injuries had persisting disability in $48 \%$ and chronic pain in $45 \%$ of cases. Functional problems with activities of daily living, work, sport and mobility were reported in up to $38 \%$ of patients. Persisting disability was seen in patients with fractures of the upper limb in $66 \%$ of cases and chronic pain was reported in $62 \%$ of these cases. Functional problems with activities of daily living, work, sport and mobility were reported in up to $66 \%$ of these patients. The author questioned whether earlier and better fixation and rehabilitation of fractures in severely injured patients might improve these results [15]. Although there is no literature about the optimum timing of surgical treatment for fractures of the upper extremities in multiply injured patients, shaft fractures should be surgically managed soon after diagnosis [16]. Tscherne et al. published a hierarchy of urgency for the operative treatment of fractures in the polytrauma patient. While treatment of upper extremity fractures follows management of the tibia, femur, pelvis and spine it precedes complex joint reconstructions, definitive treatment of maxillofacial injuries and soft tissue reconstruction [17]. As the multiply injured patient is always included in heterogeneous groups, there are no comparative studies that deal specifically with the most suitable operative procedure in fractures of the upper extremity [18-23].

Further studies have shown that missed injuries and delayed diagnoses cause significantly longer hospital stays (15.7-42.1 days vs. 7.9-26.7 days) in polytrauma 
patients. These patients also stayed in the intensive care unit for a prolonged period (5.4-10.9 days vs. 1.5-5.7 days) $[4,5,24,25]$. The present study supports these findings and underlines the importance of early diagnosis of all relevant injuries. High rates of mortality have been reported in polytrauma patients with missed injuries and there is evidence for a relationship between delayed diagnosis and morbidity [12].

The rate of missed injuries needs to be reduced. Clinical and radiological examinations remain of great importance. While it is easier to make the correct diagnosis in clinically alert patients, the examiner should be aware of missed injuries in unconscious and intubated patients. Here further diagnostic tools would be beneficial [26-28]. Some studies have revealed a lack of admission radiographs of the injured area as one reason for overlooked injuries and others have reported misinterpreted $\mathrm{x}$-rays [29,30]. Clinical experience and assessment errors were also found to play an important role $[4,5,13,31,32]$. It is rare that just one factor leads to the lack of diagnosis. More commonly a combination of different factors is responsible for missing an injury [32]. As mentioned above a polytrauma patient with reduced consciousness or that is unconscious and intubated needs careful attention during the primary and secondary survey. A tertiary survey helps to determine initially overlooked injuries within $24 \mathrm{~h}$ of admission. Up to $90 \%$ of clinically significant injuries that were initially not diagnosed were found during a tertiary survey [32]. Although the timing of a tertiary survey may vary and the patient could be examined before leaving the intensive care unit [5], it is helpful to have a conscious patient for this survey. Algorithms in our department were adapted towards a tertiary survey. Even though a tertiary survey should be performed there is no doubt that any injury should be diagnosed and treated as soon as possible. Therefore it is helpful to have indicators for further injuries.

This study is limited by its retrospective design and the small number of polytraumatized patients with a clavicular fracture in a single center institution. However, our hypothesis that a clavicular fracture indicates the presence of further injuries that might be missed during a primary survey was supported. These findings are important as a clavicular fracture in a polytrauma patient directs attention to otherwise overlooked injuries of the upper extremities. In addition, patients with a clavicular fracture are more severely injured than patients without a clavicular fracture. Based on our data we conclude that a clavicular fracture can be seen as an indicator of injury in polytrauma patients. Although adapting the trauma algorithm on primary survey is not necessary we pay special attention to the upper limb region especially in secondary and tertiary survey when a clavicular fracture is found. Beside reevaluation of standard blood tests, a tertiary trauma survey should be performed on an alert patient that is able to express pain during clinical assessment and involve careful review of initial x-rays. Attention must be paid to nerval and vascular injuries as well as covered soft tissue and ligamentous lesions. Due to the fact that musculoskeletal injuries are usually missed until tertiary survey, an experienced orthopaedic surgeon must be involved by then.

Further studies must identify the specific injury patterns that are associated with fracture of the clavicle in polytraumatized patients.

\section{Advances in knowledge}

This is the first study focusing on clavicular fracture as an indicator of further injuries in polytrauma patients.

\section{Competing interests}

The authors declare that there are no conflicts of interest including financial, consultant, institutional and other relationships.

\section{Authors' contribution}

The work presented here involved the collaboration of all authors. KH, TD and MP defined the research theme and designed the methods, collected and analyzed the data, interpreted the results and wrote the paper. RP, FH and HCP worked on interpretation and discussed the analyses, interpretation, and presentation. HCP gave critical and final approval. All authors have contributed to, seen and approved the manuscript.

\section{Acknowledgements}

The article was proofread by Proof-Reading-Service.com, Devonshire Business Centre, Works Road, Letchworth Garden City, SG6 1GJ, United Kingdom.

Received: 2 May 2013 Accepted: 25 June 2013

Published: 4 July 2013

\section{References}

1. Arbeitsmedizin BfAu: Unfallstatistik: Unfalltote und Unfallverletzte 2010 in Deutschland; 2010. Available from: http://www.baua.de/de/Informationenfuer-die-Praxis/Statistiken/Unfaelle/Gesamtunfallgeschehen/pdf/ Unfallstatistik-2010.pdf?_blob=publicationFile\&v=3

2. DGU GTS: S3 - Guideline on treatment of patients with severe and multiple injuries; 2010. Available from: http://www.awmf.org/leitlinien/detail/II/012019.html

3. Pfeifer R, Pape HC: Missed injuries in trauma patients: a literature review. Patient Saf Surg 2008, 2:20.

4. Buduhan $\mathrm{G}, \mathrm{McRitchie}$ DI: Missed injuries in patients with multiple trauma. J Trauma 2000, 49(4):600-605.

5. Kalemoglu M, Demirbas S, Akin ML, Yildirim I, Kurt Y, Uluutku H, et al: Missed injuries in military patients with major trauma: original study. Mil Med 2006, 171(7):598-602.

6. Guly HR: Diagnostic errors in an accident and emergency department Emerg Med J 2001, 18(4):263-269.

7. Kovacic J, Bergfeld J: Return to play issues in upper extremity injuries. Clin J Sport Med 2005, 15(6):448-452.

8. Southern S, Sloan J: Soft tissue injuries: chapter 8 forearm, hand and wrist. Emerg Med J 2010, 27(2):133-140.

9. Williams BG, Hlaing T, Aaland MO: Ten-year retrospective study of delayed diagnosis of injury in pediatric trauma patients at a level II trauma center. Pediatr Emerg Care 2009, 25(8):489-493.

10. David T: Missed upper extremity fractures in athletes. Curr Sports Med Rep 2002, 1(6):327-332

11. Gonzalez RP, Falimirski ME: The utility of physical examination in proximity penetrating extremity trauma. Am Surg 1999, 65(8):784-789.

12. Vles WJ, Veen EJ, Roukema JA, Meeuwis JD, Leenen LP: Consequences of delayed diagnoses in trauma patients: a prospective study. J Am Coll Surg 2003, 197(4):596-602. 
13. Houshian S, Larsen MS, Holm C: Missed injuries in a level I trauma center. J Trauma 2002, 52(4):715-719.

14. Stalp M, Koch C, Ruchholtz S, Regel G, Panzica M, Krettek C, et al: Standardized outcome evaluation after blunt multiple injuries by scoring systems: a clinical follow-up investigation 2 years after injury. J Trauma 2002, 52(6):1160-1168.

15. Mkandawire NC, Boot DA, Braithwaite IJ, Patterson M: Musculoskeletal recovery 5 years after severe injury: long term problems are common. Injury 2002, 33(2):111-115.

16. Rommens PM, Vansteenkiste F, Stappaerts KH, Broos PL: Indications, dangers and results of surgical treatment of humeral shaft fractures. Unfallchirurg 1989, 92(12):565-570.

17. Tscherne H, Regel G, Pape HC, Pohlemann T, Krettek C: Internal fixation of multiple fractures in patients with polytrauma. Clin Orthop Relat Res 1998, 347:62-78.

18. Bleeker WA, Nijsten MW, ten Duis HJ: Treatment of humeral shaft fractures related to associated injuries. A retrospective study of 237 patients. Acta Orthop Scand 1991, 62(2):148-153.

19. Bell MJ, Beauchamp CG, Kellam JK, McMurtry RY: The results of plating humeral shaft fractures in patients with multiple injuries. The Sunnybrook experience. J Bone Joint Surg Br 1985, 67(2):293-296.

20. Rommens PM, Blum J, Runkel M: Retrograde nailing of humeral shaft fractures. Clin Orthop Relat Res 1998, 350:26-39.

21. Brumback RJ, Bosse MJ, Poka A, Burgess AR: Intramedullary stabilization of humeral shaft fractures in patients with multiple trauma. J Bone Joint Surg Am 1986, 68(7):960-970.

22. Rommens PM, Verbruggen J, Broos PL: Retrograde locked nailing of humeral shaft fractures. A review of 39 patients. J Bone Joint Surg Br 1995, 77(1):84-89.

23. Vander Griend R, Tomasin J, Ward EF: Open reduction and internal fixation of humeral shaft fractures. Results using $\mathrm{AO}$ plating techniques. J Bone Joint Surg Am 1986, 68(3):430-433.

24. Rizoli SB, Boulanger BR, McLellan BA, Sharkey PW: Injuries missed during initial assessment of blunt trauma patients. Accid Anal Prev 1994, 26(5):681-686,

25. Robertson R, Mattox R, Collins T, Parks-Miller C, Eidt J, Cone J: Missed injuries in a rural area trauma center. Am J Surg 1996, 172(5):564-567. discussion 7-8.

26. Hilty MP, Behrendt I, Benneker LM, Martinolli L, Stoupis C, Buggy DJ, et al: Pelvic radiography in ATLS algorithms: a diminishing role? World J Emerg Surg. 2008, 3:11.

27. Guillamondegui OD, Pryor JP, Gracias VH, Gupta R, Reilly PM, Schwab CW: Pelvic radiography in blunt trauma resuscitation: a diminishing role. J Trauma 2002, 53(6):1043-1047.

28. Pehle B, Nast-Kolb D, Oberbeck R, Waydhas C, Ruchholtz S, Pehle B, NastKolb D, Oberbeck R, Waydhas C, Ruchholtz S: Significance of physical examination and radiography of the pelvis during treatment in the shock emergency room. Unfallchirurg 2003, 106(8):642-8.

29. Born CT, Ross SE, lannacone WM, Schwab CW, DeLong WG: Delayed identification of skeletal injury in multisystem trauma: the 'missed' fracture. J Trauma 1989, 29(12):1643-1646.

30. Kremli MK: Missed musculoskeletal injuries in a University Hospital in Riyadh: types of missed injuries and responsible factors. Injury 1996, 27(7):503-506.

31. Chan RN, Ainscow D, Sikorski JM: Diagnostic failures in the multiple injured. J Trauma 1980, 20(8):684-687.

32. Janjua KJ, Sugrue M, Deane SA: Prospective evaluation of early missed injuries and the role of tertiary trauma survey. J Trauma 1998, 44(6):1000-1006. discussion 6-7.

doi:10.1186/1754-9493-7-23

Cite this article as: Horst et al:: Risk stratification by injury distribution in polytrauma patients - does the clavicular

fracture play a role? Patient Safety in Surgery 2013 7:23.

\section{Submit your next manuscript to BioMed Central and take full advantage of:}

- Convenient online submission

- Thorough peer review

- No space constraints or color figure charges

- Immediate publication on acceptance

- Inclusion in PubMed, CAS, Scopus and Google Scholar

- Research which is freely available for redistribution

Submit your manuscript at www.biomedcentral.com/submit
Biomed Central 